\title{
Trucker's Succour a Mobile Application for Backing Truck Drivers
}

\author{
G. Soundarya, S. Preethi, J. Naskath
}

\begin{abstract}
Commercially, innumerable consignments of valuable freight are moved across India every day. On certain routes, there is always a lurking threat to the security of the freight and finding good food is also problematic for the truckers. Truck drivers have a high rate of occupation-related injury and the highest rate of on-job fatality. This project aims to develop an android application for android operating system (OS) platform which helps drivers to get help from their passersby or forthcoming trucks and send alert to their owners if there is any threat in their routes. The Owners can monitor the movement of their trucks and the threats as well. This ensures better communication with drivers on the fleet on the same route under a single corridor. This app is developed using the platform Android Studio which is a free and open-source software.
\end{abstract}

Keywords: Truckers Helpline, Android Studio, Mobile Application, Alert Message, Firebase.

\section{INTRODUCTION}

Truckers Succour is a mobile application developed for backing truck drivers. This app works as a helpline, where no intermediate is needed. Transport is the largest business in India. It plays an essential role in the Indian economy. Once drivers start the journey, they are fully responsible for the timely delivery of goods to the destination. Truck drivers are working for long hours, with the days turning into months and months into years. There are many challenges for truck drivers while they are running on National Highways because of the lack of awareness among truckers and transporters.

Trucks, truck drivers, and truck materials are always not safe on highways. The truckers may face challenges like highway robberies, which is to be noted as a critical issue. Roads may create hindrance during transportation due to lack of properly conditioned road constructions. Still, there is a lack of roadside shops, repairing shops, dhabas, rest places, etc. due to which truckers have to face problems. If truckers face technical issues in trucks, they have the option of calling helpline call centers. They could fix it by 2 to 4 hours. But, if

Manuscript received on April 30, 2020.

Revised Manuscript received on May 06, 2020.

Manuscript published on May 30, 2020.

* Correspondence Author

G. Soundarya*, Computer Science and Engineering, National Engineering College, Kovilpatti, India. Email: soundarya30698@gmail.com

S. Preethi, Computer Science and Engineering, National Engineering College, Kovilpatti, India. Email: preethitac28@gmail.com

J. Naskath, Computer Science and Engineering, National Engineering College, Kovilpatti, India. Email: naskat@nec.edu.in

(C) The Authors. Published by Blue Eyes Intelligence Engineering and Sciences Publication (BEIESP). This is an open access article under the CC BY-NC-ND license (http://creativecommons.org/licenses/by-nc-nd/4.0/) truckers face fundamental issues like route diversion, health issues, difficulty in finding fuel and foods, there is still no solution.

The main aim of this application project is to get help from co-truck drivers who are traveling on the same route. This helps them to get their needs within 1 hour. Nowadays, 91 percent of people in India use Android Mobile phones. Most of the smartphones equipped with computer processing ability are used to access networks and use different applications developed to meet the user requirement via mobile communication networks. In last seven years, different android Mobile applications have been developed, including top paid and free apps focusing on GPS. So, this app will create a significant impact among owners, drivers, and other people.

Trucker's Succour is an android application developed using the software called Android Studio. Android studio is a new IDE (Integrated Development Environment) made available at no cost Google to Android Developers. It includes many tools to develop the application. It uses SDK Emulator to implement some features of Android devices like launch google Browser, connect with internet, send messages, view the essential information of the device (memory space, and security). Android applications are written using Java as a programming language but are executed using accustom virtual machine called Dalvik instead of a traditional Java VM, Each Android application runs in a very separate process within its own Dalvik instance, relinquishing all responsibility for memory and process management to the Android run time, which stops and kills processes as necessary to manage resources [26]. The android is software that was founded in Palo Alto of California. Android is an open source OS which provides many features. Android is Open Source Project so customize the OS based on our requirements. Android supports differing kinds of connectivity for Bluetooth, CDMA, WIFI, GSM etc. for data transfer or telephonic conversation. It contains multiple APIs to support a location-tracking services like GPS. The application tracks down the current location of the driver phone when they click on threat button in the form of Latitude and Longitude. Then it is converted into a full address and it is also sent to an online server database using IMEI (International Mobile Station Equipment Identity) that can be used to find out the user's last updated Location Address, which helps owners to track them. This also send as alert message to other drivers who registered in this application. The main advantage of this application is that there is no intermediate between the driver who needs help and the driver who is providing the help. 


\section{LITERATURE SURVEY}

The main goal of a scientific literature review is to search out relevant literature within the discipline. Shirin Salim, Dipina Damodaran B \& Surekha Marium Vargese (2016).'Mobile Tracker' [1]. International Journal on Cybernetics \& Informatics (IJCI).

This paper of Shirin, Salim \& Surekha designed a tracking mobile application to detect the lost mobile phones by using their IMEI number. In this app, when an unauthorized sim card is inserted during a lost mobile, it sends messages during a predefined format to a registered mobile number. Ahemad Tutake, Abhijeet Tekawade, Pranay Dhole, Ravindra Shinde \& Mr. Sumit Hirve (2013). 'Mobile Tracking Application for Locating Friends using LBS' [2]. International Journal of Innovative Research in Computer and Communication Engineering. This article, they designed an application that uses the user's geographical location, which consists of $\mathrm{X}$ and Y coordinates, which is generated by GPS, which acts as a positioning device. This paper called a mobile tracking application for locating friends using LBS, which uses GPS as a location provider through a geographic location. This application has an anti-theft facility for the users who is using the app so his/her location information is distributed to the geographically nearest police office. Palash Uddin, Zahidul Islam \& Nadim (2013). 'GPS-based Location Tracking System via Android Device' [3]. International Journal of Research in Computer Engineering and Electronics, ISSN 2319-376X. This article designs an application for tracking location of a group of individuals with a alert system using various latest tools and technology like Jason, Java, AVD, LAMP, etc. Amit Kushwaha \& Vineet Kushwaha (2011). 'Location Based Services using Android Mobile Operating System' [5]. International Journal of Advances in Engineering \& Technology. This article of Amit \& Vineet designed an Android-based tracking system, which facilitate users to chase out nearest vital locations sort of a hospital, market, ATM booth, School, etc. Mia Md. Karimul Hoq, Muhammad Jahangir Alam \& Md. Nurul Mustafa (2017). 'Mobile following System exploitation net Application and golem Apps' [6]. International Journal of Engineering analysis and Technology, ISSN: 2278-0181. This article by Karimul, Vineet \& Nurul designed a Mobile Tracking System by which parents can track their children's location. Text messages is also shared with online users. Ch. Radhika Rani, A. Praveen Kumar, D. Adarsh, K. Krishna Mohan, K.V. Kiran (2012). "LOCATION-BASED SERVICES IN ANDROID" [8]. International Journal of Advances in Engineering \& Technology, ISSN: 2231-1963. This article by Radhika, Praveen, Adarsh, Krishna, and Kiran designed an Android app which inputs two addresses from the user, one is the source address, and another is that the destination address then shows the route between these 2 locations. Gigih Forda Nama, Fadillah Halim Rasyidy, Raden Arum S P\&Mardiana (2018). 'A Real-time Schoolchild Shuttle Vehicle Tracking System Base on Android Mobile-apps' [22]. International Journal of Engineering \& Technology, 7 (3.36) (2018) 40-44. This article of Forda, Halim, Arum \& Mardiana designed android-based mobile apps and web technology for schoolchild shuttle applications which sends the situation and displays the vehicle shuttle location on the smart phone screen and also displays the historical location of the tracked school vehicle. Navod K Payagala \& Arunthavanathan Rajeevan (2016).'Vehicle Monitoring Controlling and Tracking System by Using Android Application' [23].International Journal of Technical Research and Applications. This article by Rajeevan \& Payagala describes the vehicle tracking design by integrated engineering technology. It represents the look and implementation of auto tracking, vehicle monitoring, controlling and vehicle status notification anywhere by using mobile applications. Sagar Tete, Shailesh Sahare, Diksha Likhar \& Reshma Badalu (2018). 'Android App: Vehicle Tracking System' [24]. International Research Journal of Engineering and Technology (IRJET), e-ISSN: 2395-0056. This article, Tete, Sahare, Likhar \& Badalu designed a mobile application for taxi owners, drivers \& customers to search out the location of the taxi using GPS navigation. this might help the taxi drivers to record the attendance of drivers which helps in calculating their salary.

\section{EXISTING SYSTEM}

In the existing system, Truckers get their necessities through service centers within 2 to 4 hours. There will be an intermediator between truck drivers and service providers. Tata Motors provides Accidental Renovation Incident Management process, which is an end to end support for damaged vehicles in shops. Insurance team of TATA Motors registers the complaint for survey or appointed cases in CRM for accidental repairs. Complaints are assigned to respective dealerships. Complaints follow up when close looping is done and the complaint is followed up until the vehicle work is completed and released from the workshop. Post complain closure satisfaction check is also done after seven days to get the customers to feedback on work done by the dealership. Toll-Free number 18002582553 is a dedicated helpline for Tata Motors Channel partners for any queries and concerns. This single window contact has been designed for them to seek support on a resolution of their issues. TATA Alert is a program for Commercial Trucks customers for vehicles running on all National Highways for specified Models. Ashok Leyland avails Quick Response where the recovery within four hours anywhere, anytime and avails vehicle renovation within 48 hours. MAHINDRA provides its unique helpline to provide reliable advice and immediate aid anytime and anywhere for Mahindra Trucks and Buses. Drivers just have to call up the number and ask for assistance in the language of their choice. Thus, drivers in India can feel comfy while talking to the servants and explain their requirements. It mean that downtime of vehicle is reduced and guaranteed high performance. TRUCK DRIVER POWER (TDP) is a mobile app, which gives features that give drivers the tools they need to advance their career, stay safe on the road and connect with their circle, which is used only now in America. Thus, these helplines have an intermediator to connect the driver and the service provider. However, all this process takes a minimum of 1 hour to get their needs met.
Blue Eyes Intelligence Engineering \& Sciences Publication 


\section{PROPOSED SYSTEM}

The main idea of this project is to develop a mobile application for truck drivers to help them in helpless situation. Helpless situation meant here is when they face issues like fuel insufficiency, health problems, need of food at National Highways or any strange place. Major issue includes the health problems and technical issue in trucks.

This application includes tracking system using GPS. In default, every android phone contains GPS. Here, GPS used for tracking purpose is GPS in Trucker's mobile phone. This would help the truck owners to monitor their truck. This application has database storage of both drivers and owner's details. The database used is Firebase. Firebase is a platform for developing mobile and web application. First product of firebase is Real-Time Database, which is used in this application as back-end. Firebase Real-Time Database is an API used to synchronize the data of application and store it in cloud of Firebase. It works as Backend as a Service.

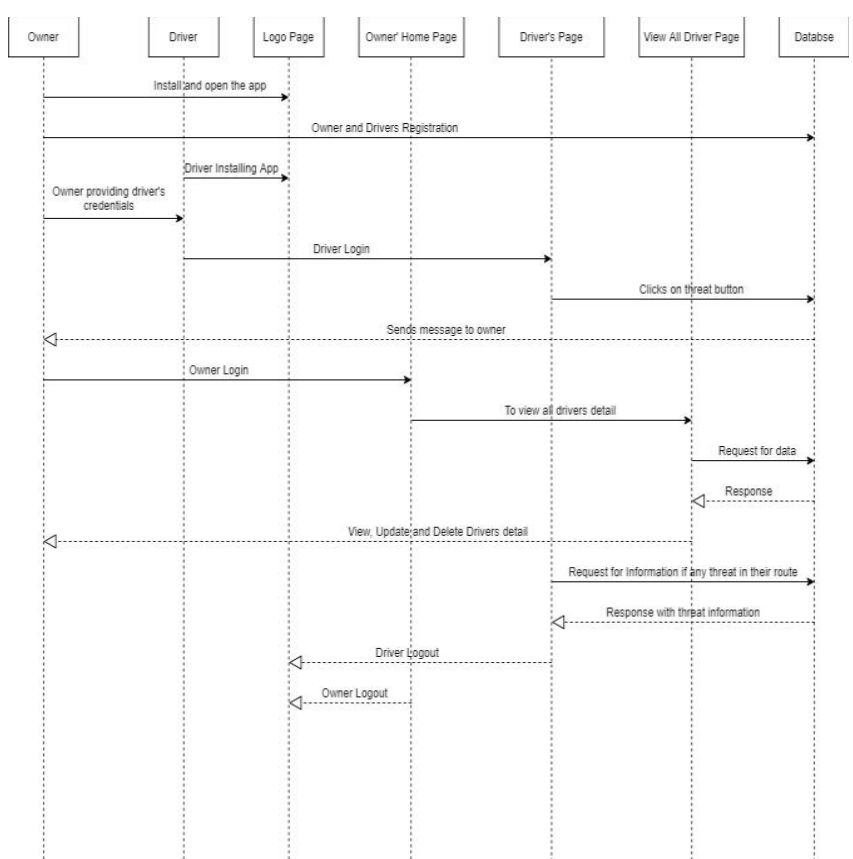

Fig 4.1 Sequence diagram of Trucker's Succour

This application has User Interface for both truck drivers and truck owners. Owners can register themselves with filling their credentials where drivers can only login into the application. Driver's login credentials were provided only by owners. This feature is included in to application to avoid fake id of drivers. Our system provides the feature of view threat in the same route where they travelling. This is possible when truckers who travel before them in the same route click on threat button. This is helpful to truckers when they are in need of help. This is also helpful to those truck drivers who is going to face treat in their route. They may know the threat by login into this application. Truck Owners can view all data of drivers and edit their details.

\section{REQUIREMENT ANALYSIS}

\section{A. Bisection of the Application}

Truckers Succour Android Mobile Application consists of the following two sections.

\section{- Owner}

- Driver

The facilities for the Owners are given below:

- Register the details in the app and create the profile

- Set the password and user name

- Start and stop services any time they want

- Add, Update and Delete drivers who are driving their truck

An Owner is a user who use the application creates his username and password so that no other person can enter on to his profile. He can add, update, and delete the details of the drivers of his trucks. They can track their trucks when they want. It allows owners to manage their tasks better.

Every driver who is tracked must have the following capabilities:

- Operate a Smartphone with Android OS.

- Must have a basic English knowledge.

Drivers can log in to the app with provided credentials. Their owner provides the credentials. The drivers' page consists of a route option list where he can select his route.

\section{B. Project Development Requirements:}

The development of the project requires two devices; it is divided into two parts.

Table- I: Requirements of Developer

\begin{tabular}{|c|c|c|c|}
\hline Devices & Personal & omputer & $\begin{array}{c}\text { Android } \\
\text { Virtual } \\
\text { Device }\end{array}$ \\
\hline \multirow[t]{2}{*}{$\begin{array}{c}\text { Hardware } \\
\text { requirements }\end{array}$} & Processor & $\begin{array}{c}\text { Pentium } \\
\text { IV or } \\
\text { higher }\end{array}$ & $\begin{array}{c}\text { Android } \\
\text { Virtual } \\
\text { Device is } \\
\text { an }\end{array}$ \\
\hline & RAM & $\begin{array}{l}128 \mathrm{MB} \\
\text { or higher }\end{array}$ & $\begin{array}{c}\text { emulator } \\
\text { which can } \\
\text { be } \\
\text { configured }\end{array}$ \\
\hline $\begin{array}{c}\text { Software } \\
\text { requirements }\end{array}$ & $\begin{array}{c}\text { Operating } \\
\text { system }\end{array}$ & $\begin{array}{c}\text { Windows } \\
-\mathrm{X} \text {, } \\
\text { Linux or } \\
\text { any other } \\
\text { OS }\end{array}$ & $\begin{array}{c}\text { with } \\
\text { Android } \\
\text { Studio. } \\
\text { Need to } \\
\text { have } \\
\text { Android } \\
\text { OS. }\end{array}$ \\
\hline
\end{tabular}

\section{Application User Requirements}

\section{Smartphones with Android OS}

- Internet

- GPS

- Android OS version 2.2 or higher

\section{METHODOLOGY}

The only reason for choosing Android application is that it is more popular among users. It is less expensive too. Name of the application for this project is "Truckers Succour" mobile application. Truckers Succour is android based mobile application that works on all android mobile phones.

Published By:

Blue Eyes Intelligence Engineering

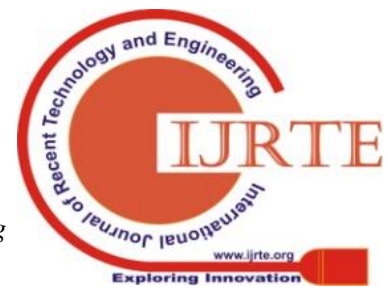


This application has two modules, which consists of owner and driver side. Owner is the owner of the truck and Drivers are driver who drives their trucks.

Owner need to register first and creates an account. While creating an account he needs to provide certain information like their name, phone number, location, password, number of trucks. Owners can edit or update their own details and drivers' details.

Their page contains details of their drivers. Drivers are added by their owners. Drivers have ability to login, only if they get registered by their owners because login credentials are provided by them. Driver's login credentials include mobile number and password. Mobile number is driver's mobile number which used for registration and password is set by owner on his own choice. After login process they are redirected to driver's page. They can select route they travel and mark threat if they are in problem. While clicking the threat button their current location is stored as latitude and longitude in owner's database as driver's data and also it is sent as alert notification to other drivers who travelling on the same fleet on the same path, so that they can get help or solution to their problem. The proposed system can be implemented using the mobile data services in smart phones.

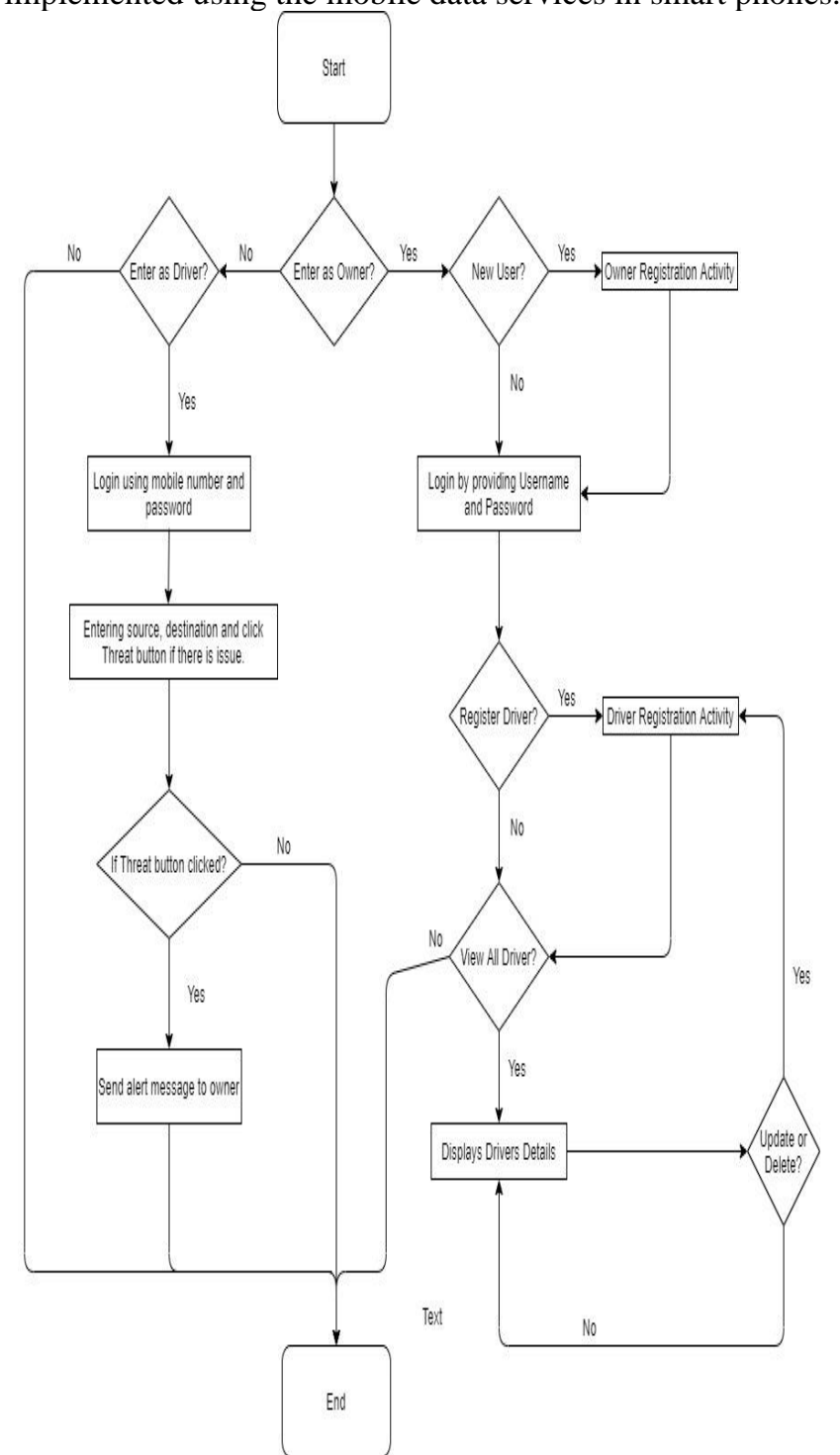

Fig 6.1 Work Flow Diagram

\section{A. Module Design}

This project has two modules; they are owner module and driver module. Logo Page is the first starting page of truckers succour. It has two buttons; one is for owner and other is for driver.

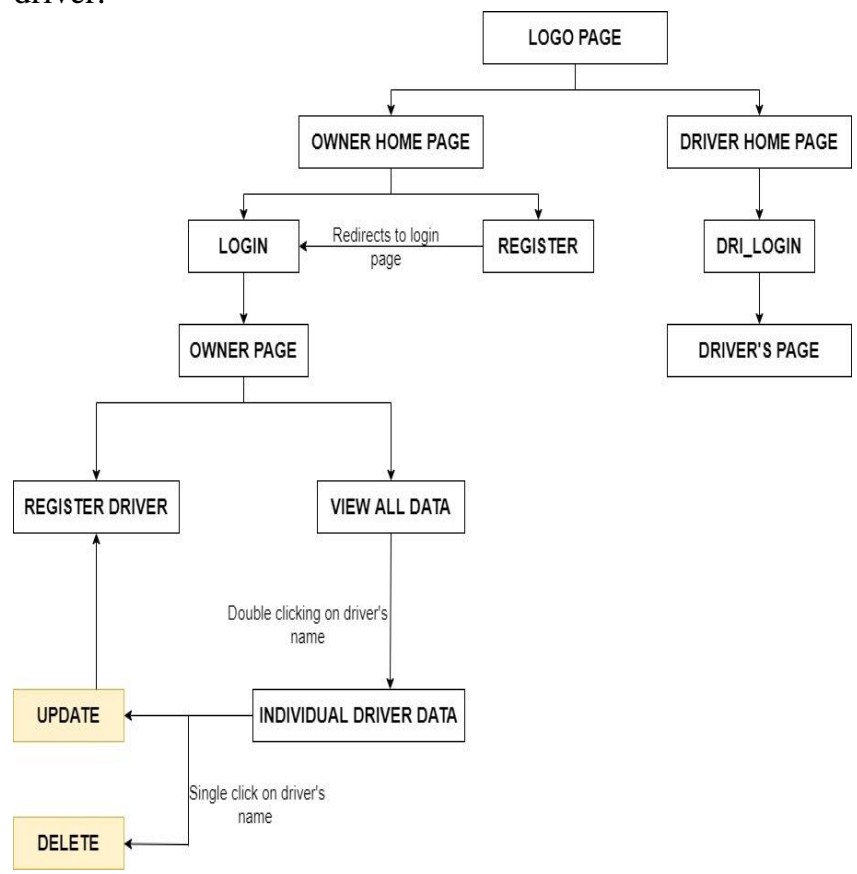

Fig 6.1.1 Architecture Diagram

\section{Module 1: OWNER}

This module contains various sub modules.

Owner Homepage: Owner Homepage is for owner registration and login purpose. It contains two buttons: Owner Registration and Owner. Owner Registration redirects to registration page of owner and Owner button redirects to login page of owner. Owner Homepage can be opened using owner button in logo page.

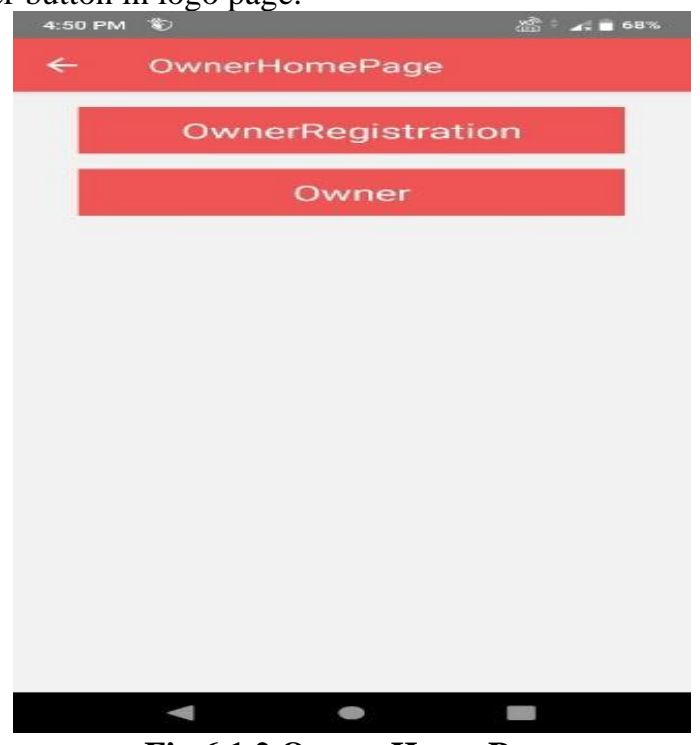

Fig 6.1.2 Owner Home Page

Owner Login Page: Login Page of owner redirects the owner to Owner Page. They can login only if they provide correct credentials and details given while registration. 
Owner can login using username and password. Once owner didn't register, they can click on register button in login page which redirects them to Register Page.

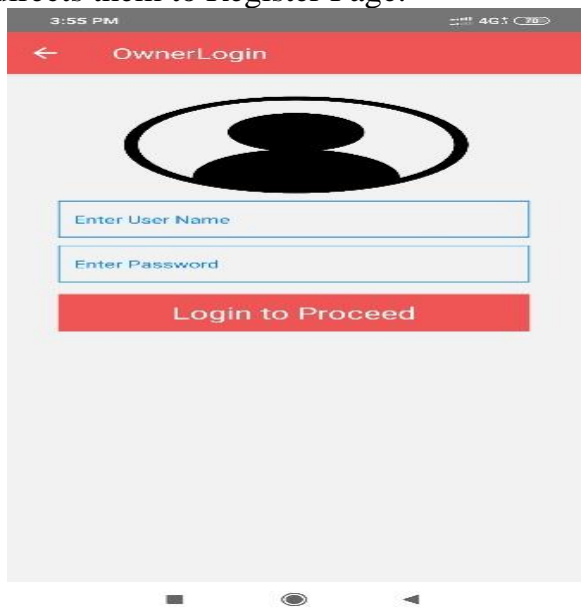

Fig 6.1.3 Owner Login Page

Owner Registration: Owner Registration page is to register the owner by entering some of their details. Login credentials are provided only if they registered. While registration they have to provide the following details: Name, Phone Number, Location, Number of Trucks, Password, Confirm Password.

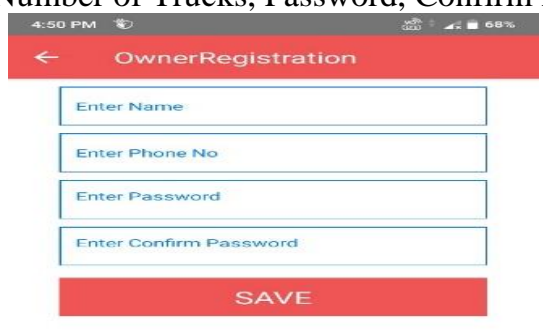

\section{Fig 6.1.4 Owner Registration Page}

Owner Page: Owner page is the page opens after owner login. It contains two buttons: Register Driver and View All Driver, which redirects them to corresponding pages. When you click on Register Driver button it redirects to Driver's Registration page where you can register any number drivers under single owner. View All Driver page is a page which displays all driver details of a owner.

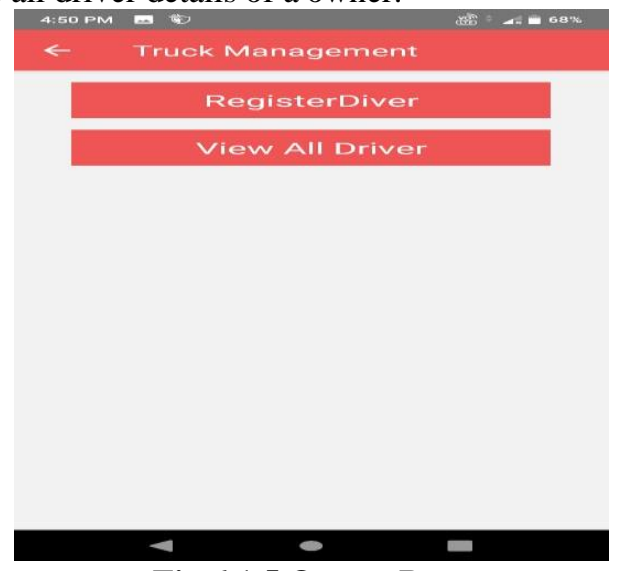

Fig 6.1.5 Owner Page
View All Driver: This page contains all drivers details under particular owner i.e., it shows all drivers name of that owner. While double clicking on driver's name redirects to another page which contains all details of that driver. Also it has two buttons Update and Delete. Once you click on Update button it redirects to Drivers Registration Page. Delete button for deleting a driver details from database.

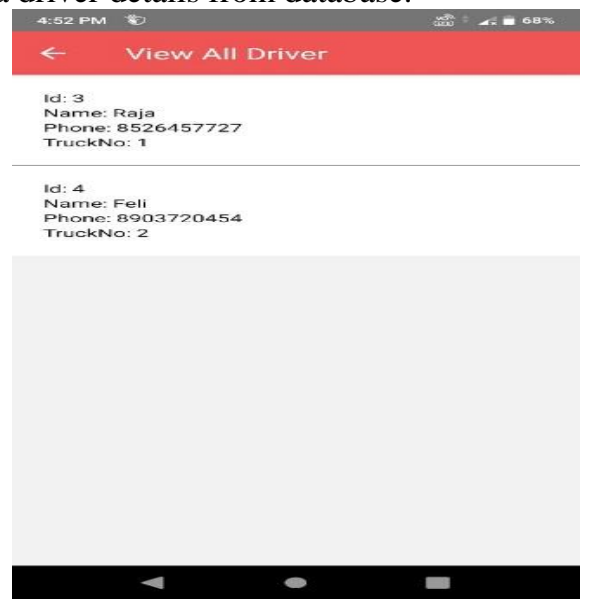

Fig 6.1.6 View All Driver Page

Drivers Registration Page: Drivers Registration page is used to register driver under a owner. A owner can register any number of drivers based on their needs and number of trucks. Owners can register their drivers using this page. Registration details to be entered are Name, Phone Number, Date Of Birth, Truck Number, Password, Confirm Password.

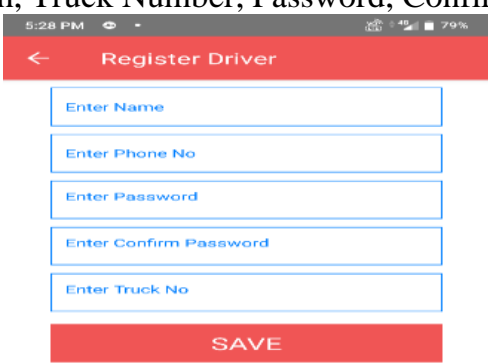

\section{Fig 6.1.7 Driver Registration Page}

\section{Module 2: Driver}

Driver Login Page: Driver Login page is the page where a driver can login into their page. They can login here by entering their registered Mobile Number and given password. Password is provided by their owners where Mobile Number is the number given to their owners for registration. Owners only can register their drivers, so that fake drivers can be avoided. 


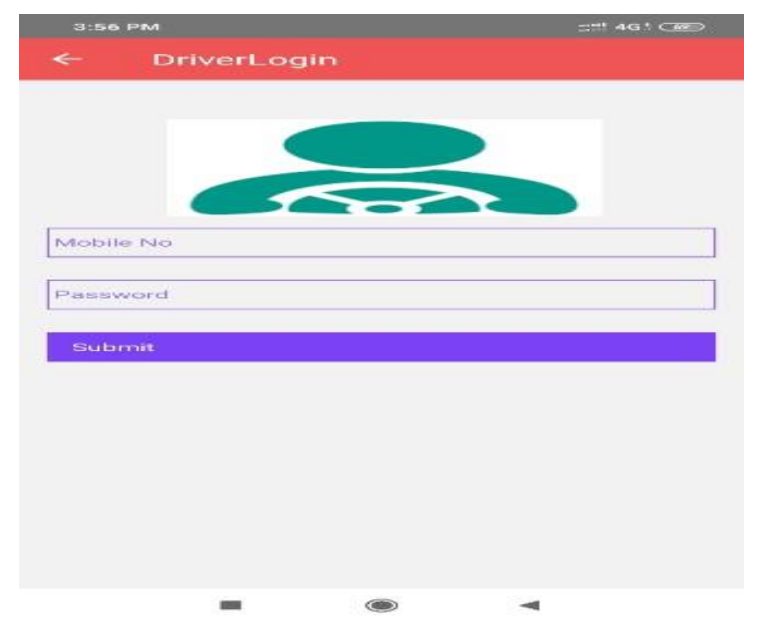

Fig 6.1.8 Driver Login Page

Drivers Home Page: Home Page of Drivers contains Threat button and Find button. Drivers have to provide their route from source to destination. Their current location will be displayed as address automatically by GPS feature in their android mobile phone. Threats can be marked using button provided in this page, which stores current location as latitude and longitude in owner's database which can be viewed by owner and also it sends as alert message with issue type to the drivers on the same fleet on the same route. The alert message is sends in the format given below:

Problem: (Remarks given in the textbox)

Address: (Current location address when driver clicks on threat button)

Find button is used to find the threat in their routes. Once the driver clicks on the Find button by giving source and destination, a pop-up message with threat in their route is displayed. If there is no threat in their route, then is displays a pop-up message with 'No Threat'.

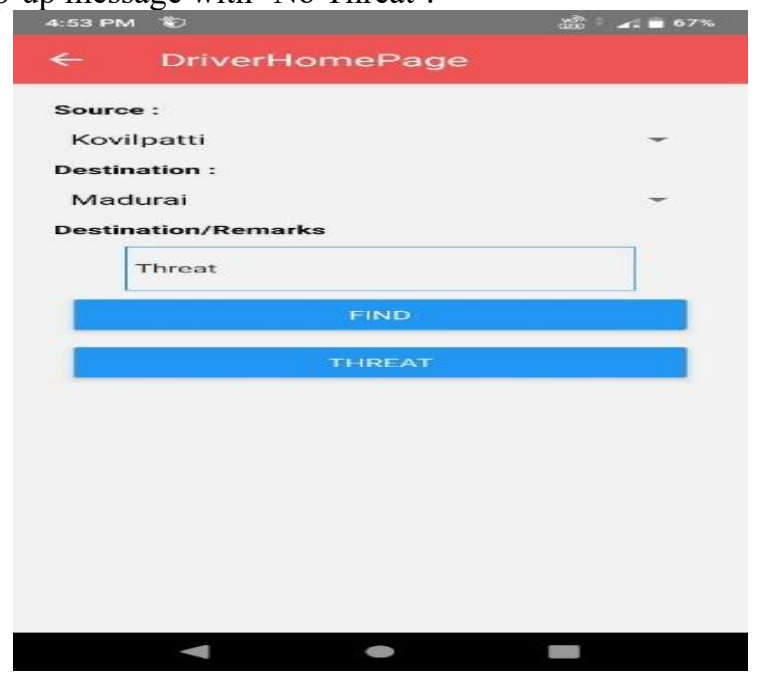

Fig 6.1.9 Drivers Home Page

Fig-6.1.1 shows the architectural diagram of the project. It starts or opens with the logo page, which contains two optional buttons, one is for the owner, and the other is for the driver. They have their functionalities so that the project can run by both end-users.

\section{RESULTS AND DISCUSSION}

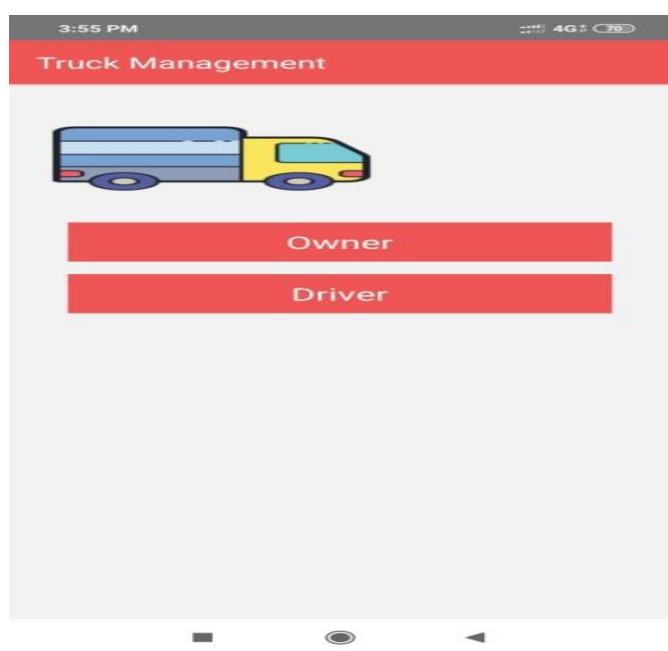

Fig 7.1 Logo Page

Logo Page is the first or starting page of Truckers Succour mobile application. Fig 7.1 shows the logo page. It contains two options which when selected redirects to owner homepage (while clicking owner button) and driver homepage (while clicking driver button) accordingly. Separate logins are allocated for owners and drivers to avoid fake drivers accounts. Owners can register by their own where drivers are registered only by the owners. Driver login is based on the credentials allocated by the owner. Owner can login using their Mobile number and password created while registration as login credentials.

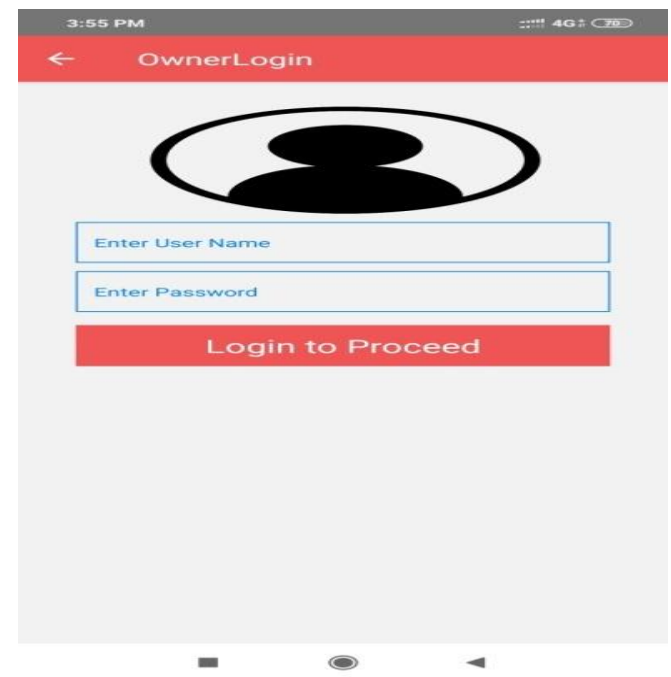

Fig 7.2 Owner's Login Page

Owner's Login page opens when they click on owner button on Owner Home page. Fig 7.2 shows the owners' login page with two text boxes and one button. Text boxes for username, another one for password and button to login. Using this page, registered owners can log in to the app. They have to provide their registered mobile number as username and password to login. Once they login by providing correct credentials, it redirects to Owners page. If he/she is a new user, they can sign up as a new owner by providing their details along with the driver details. 


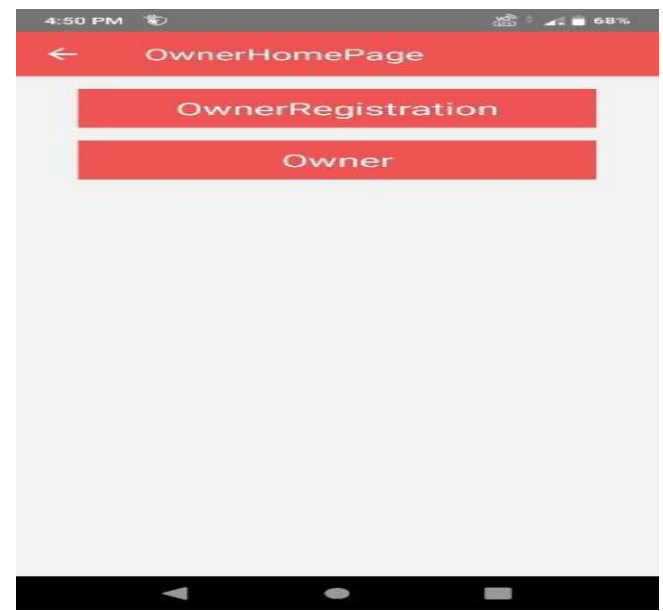

Fig 7.3 Owner Home Page

Owner Home Page is the page of owner, where they can register and login into the app. The person who doesn't register in this application cannot able to log in. This page helps to choose an option for registration or login. This page has two buttons: one is Owner registration which redirects to Owner Registration Page and other is Owner button which redirects to owner login page. Fig 7.3 shows the owners home page where you have an option for registration and login. Only the registered owners can login to the app.

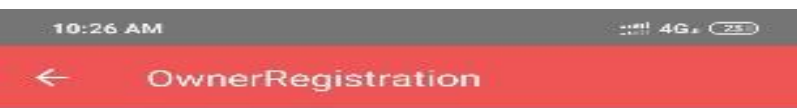

\begin{tabular}{|l|}
\hline Enter Name \\
\hline Enter Phone No \\
\hline Enter Password \\
\hline Fnter Confirm Password \\
\hline
\end{tabular}

SAVE

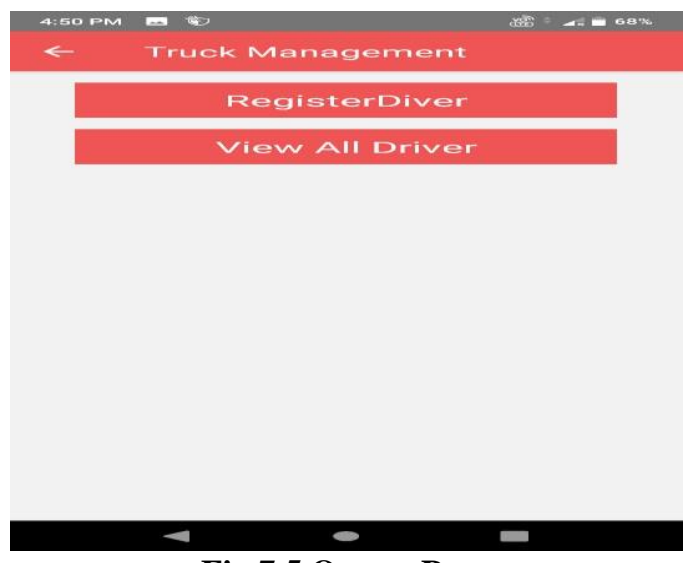

Fig 7.5 Owner Page

Owner page is the page opens after owner login. It is named as Truck Management in this application. This page contains two buttons: Register Driver and View All Driver. Fig 7.5 displays Owner Page which contains those buttons. When you click on Register Driver button it redirects to Driver's Registration page where you can register any number drivers under single owner. Owner has the facility to add driver and view their driver's details. They can add one or more than one driver. View All Driver page is a page which displays all driver details of an owner. Drivers details contains their names, phone number, their password and truck number which they driving.

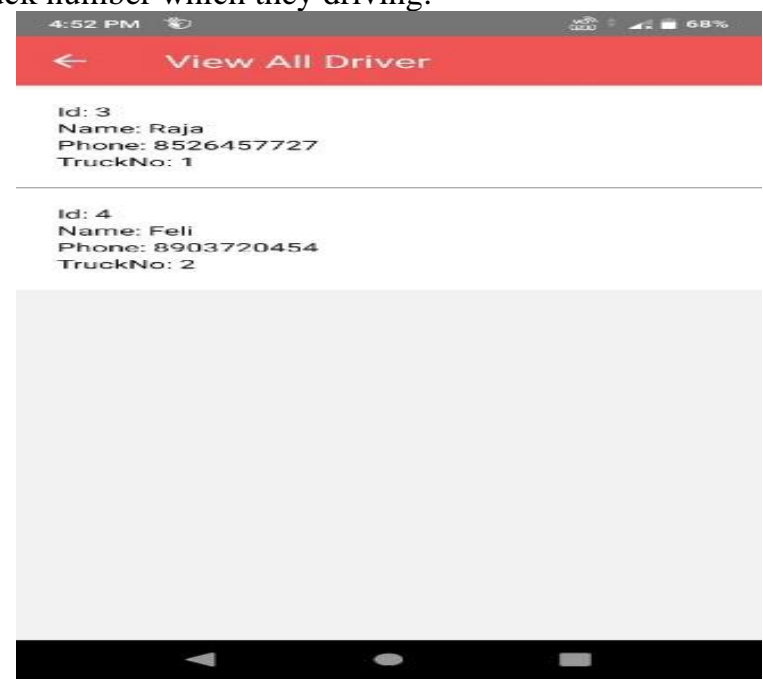

Fig 7.6 View All Driver Page

View All Driver page contains all drivers details of an owner i.e., it shows all drivers name of that owner. While double clicking on driver's name redirects to another page which contains all details of that driver. Also, it has two buttons Update and Delete. Once you click on Update button it redirects to Drivers Registration Page, there you can update drivers' details like mobile number, password, truck number. Once you click on the Delete button, it deletes a driver details from database completely. Fig 7.6 displays the View All Driver Page with two driver details in list format. Any number of drivers can be added to the database of single owner, there is no limitations for number of truck drivers. With the help of the data base the owners will be able to fetch the details of any particular drivers under them. Data can be easily accessed by viewing the detailed list of drivers. 


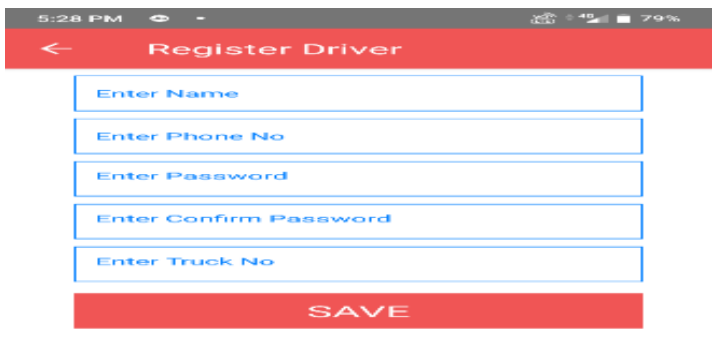

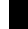

\section{Fig 7.7 Driver Registration Page}

Drivers Registration page is used to register a driver. Before registering a driver, an owner must know their drivers details to register them in to the application. Fig 7.7 shows the Drivers Registration Page, where only owners can register their driver details to avoid duplication and fake account registration. These details are stored under the respective owner's database. The driver login credentials are checked with this data base. It shows the drivers registration page with five text boxes for name, mobile number, password, truck number and one save button. An owner can register any number of drivers based on their needs and number of trucks. To register a driver some of the registration details to be entered are Name, Phone Number, Truck Number, Password, Confirm Password. Owners can register their drivers using this page.

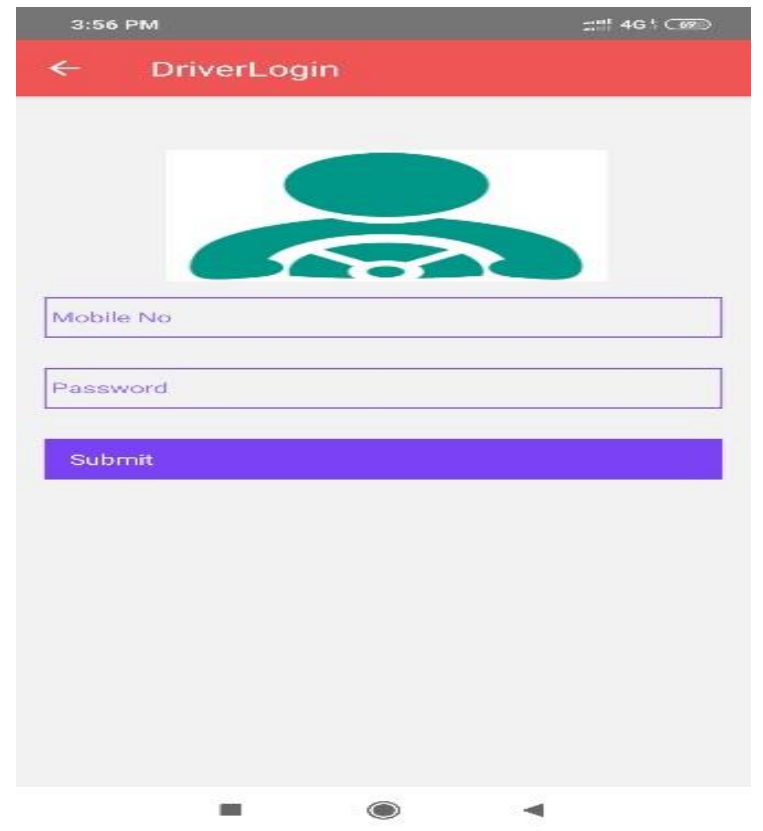

Fig 7.8 Driver Login Page

Driver Login page is used to sign in to the application. They can login here by entering their registered Mobile Number and given password. Fig 7.8 shows the Drivers Login Page, where registered drivers can log in using their Mobile Number and given Password. The mobile number and the passwords are allocated by the owners. This is to avoid the fake driver's profile. Password is provided by the owners where Mobile Number is the number given to their owners for registration. Owners only can register their drivers, so that fake drivers can be avoided.

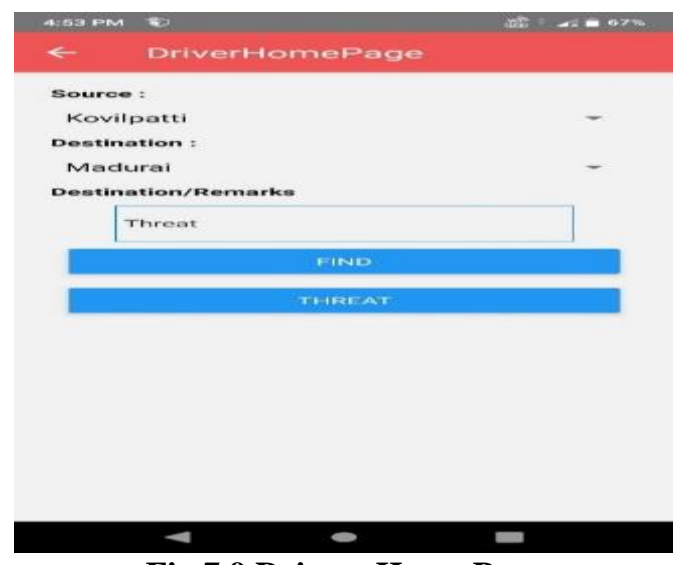

Fig 7.9 Drivers Home Page

Drivers Home page is the main part of this application. Fig 7.9 shows the home Page of Drivers which contains Threat button and Find button. Drivers have to provide their route from source to destination. Their current location will be displayed as address automatically by GPS feature in their android mobile phone. Threats can be marked using button provided in this page, which stores current location as latitude and longitude in owner's database which can be viewed by owner and also it sends as alert message to the drivers on the same fleet on the same route. The alert message is sends in the format: Problem: (Remarks given in the textbox)/ Address: (Current location address when driver clicks on threat button). Find button is used to find the threat in their routes. Once the driver clicks on the Find button, a pop-up message with threat in their route is displayed. It displays a pop-up message with 'No Threat' if there is no threat in their route.

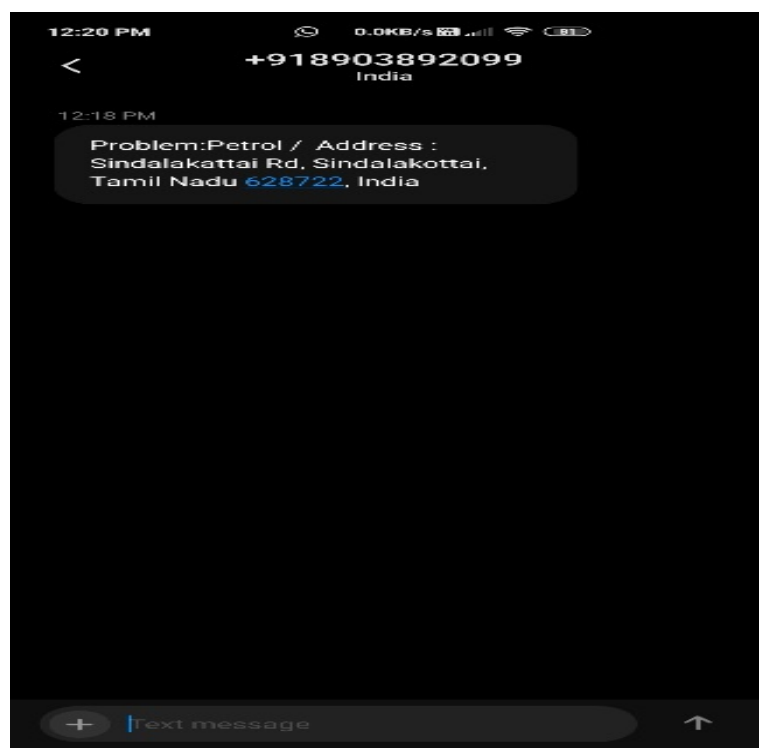

Fig 7.10 Screenshot of Message Received

When a driver faces any issue like health problem, fuel insufficiency, any mechanical, or technical issues in trucks it is send as short message service to the owner. This happens when he clicks on threat button. If a driver has no way to solve his problem self then login to the application, choose source and destination, fill the remark text box with the problem he faced and click on threat button. 
Once he clicks on button it sends message to the owner with the problem and driver's current location as address.

\section{CONCLUSION AND FUTURE SCOPE}

Truckers Succour Mobile Application is a more efficient application for truck drivers. The main objective of this project is to create user friendly mobile application for truckers and truck owners to help them in helpless situation. GPS signals are successfully received and send location information to the truck owners through android application and shows current location of truck with their issues. It assists truckers in getting help in a helpless situation at unknown places and National Highways. It is also advantageous to the drivers who were new to a particular route. It is designed as a simple one such that it is more convenient to use by both end-users as the threat is easily marked on the map and cleared. These all aspects are very important in business to remove or minimize the risk associated with vehicle management, improving efficiency, staff management, providing security, etc. In future, this app can be used by a wide range of people as personal assistants who travel alone and with family in helpless situation at unknown places. It can also be implemented as personal assistants for parents can track their children. It can add with special buttons for serious issues and with camera and microphone facility to enable video call automatically once they click on the serious issue button which helps parents to find the place of their children clearly. This application can implement with Artificial Intelligence Algorithm to send message or alert notification automatically to the persons traveling on the same route. To handle emergency situation, External Hardware can be added which is very effective. For continues tracking of truck, External GPS device can be added. For identification purpose RFID can be added. Traffic management, route optimization can also be included. Hence, we conclude that various challenges like basic needs of truck drivers were overcome using this application.

\section{REFERENCES}

1. Shirin Salim, Dipina Damodaran B, and Surekha Marium Vargese, "Mobile Tracker, "International Journal on Cybernetics \& Informatics (IJCI) Vol. 5, No. 2, April 2016.

2. Abhijeet Tekawade, Ahemad Tutake, Ravindra Shinde, Pranay Dhole, Mr. Sumit Hirve, "Mobile Tracking Application for Locating Friends using LBS," International Journal of Innovative Research in Computer and Communication Engineering Vol. 1, Issue 2, April 2013.

3. Md. Palash Uddin, Md. Zahidul Islam, Md. Nadim, "GPS-based Location Tracking System via Android Device," International Journal of Research in Computer Engineering and Electronics. 1 ISSN 2319-376X Vol. 2 Issue. 5, 2013.

4. Radhika Kinage, Jyotshna Kumari, Purva Zalke, Meenal Kulkarni, "Mobile Tracking Application," International Journal of Innovative Research in Science, Engineering and Technology Vol. 2, Issue 3 , March 2013.

5. https://www.quora.com/What-are-the-problems-faced-by-truck-driver s.

6. https://www.hotcars.com

7. https://www.nonforceddispatch.com

8. https://www.become.co/blog/6-challenges-us-trucking-industry/

9. https://www.dat.com/blog/post/top-10-issues-for-drivers-in-2019

10. https://www.joc.com/trucking-logistics

11. https://blog.transportinindia.in

12. https:// ripublication.com

13. https://www.exchange4media.com

14. Francesc Soriguera, Enric Miralles, "Driver feedback mobile app," XII Conference on Transport Engineering, CIT 2016, 7-9 June 2016.

15. https://www.mahindratruckandbus.com

16. https://www.ashokleyland.com

17. https://customercare-cv.tatamotors.com
18. Rameshwar Dubey Angappa Gunasekaran, (2015), "The Role of Truck Driver on Sustainable Transportation and Logistics," Industrial and Commercial Training, Vol. 47 Iss 3 pp.

19. Khaled Shaaban, "Drivers' Perceptions of Smartphone Applications for Real-Time Route Planning and Distracted Driving Prevention," Hindawi Journal of Advanced Transportation Volume 2019, Article ID 286724.

20. Neha Verma, Sarita Kansal, Huned Malvi, "Development of Native Mobile Application Using Android Studio for Cabs and Some Glimpse of Cross-Platform Apps," International Journal of Applied Engineering Research ISSN 0973-4562 Volume 13, Number 16 (2018) pp. 12527-12530.

21. Salman, Waheed Ahmad, Riaz Ali, Salman Saleem, "A Research on Mobile Applications for Location Tracking Through Web Server and Short Messages Services (Sms)," VFAST Transitions on Software Engineering ISSN(e): 2309-3978, ISSN(p) 2411-6246 Volume 7, Number 02, July-August, 2015.

22. Gigih Forda Nama, Fadillah Halim Rasyidy, Raden Arum S P, Mardiana, "A Real-time Schoolchild Shuttle Vehicle Tracking System Base on Android Mobile-apps," International Journal of Engineering \& Technology, 7 (3.36) (2018) 40-44, May, 2019.

23. Arunthavanathan Rajeevan, Navod K Payagala, "Vehicle Monitoring Controlling and Tracking System by Using Android Application," International Journal of Technical Research and Applications, e-ISSN: 2320-8163, Volume 4, Issue 1 (January-February, 2016), PP. 114-119.

24. Sagar Tete, Shailesh Sahare, Diksha Likhar, Reshma Badalu, "Android App: Vehicle Tracking System," International Research Journal of Engineering and Technology (IRJET), e-ISSN2395-0056, Volume05, Issue02, Feb-2018, p-ISSN2395-0072.

25. https://www.blog.quikhop.com

26. Abbey Deitel, Harvey Deitel, Paul Deitel, Android ${ }^{\mathrm{TM}}$ How to Program, Second Edition, PrenticeHall, Release Date: January 2014.

\section{AUTHORS PROFILE}

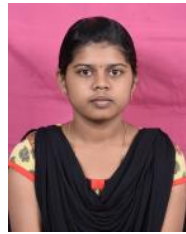

G. Soundarya, currently pursuing her Bachelor of Engineering in Computer Science and Engineering from National Engineering College, TamilNadu, India. Her area of interests is related to Mobile Application Development and Internet of Things. Email: soundarya30698@gmail.com.

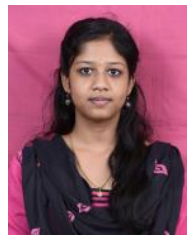

S. Preethi, currently pursuing her Bachelor of Engineering in Computer Science and Engineering from National Engineering College, TamilNadu, India. Her area of interests is related to Cloud Computing. Email: preethitac28@gmail.com.

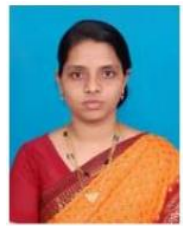

Ms. J. Naskath, received her Master of Engineering in Computer Science and Engineering from Anna University, TamilNadu, India. She is working as an Assistant Professor (Senior Grade) in National Engineering College, TamilNadu, India. Email: naskat@nec.edu.in 